San Jose State University

SJSU ScholarWorks

Master's Theses

Master's Theses and Graduate Research

1992

\title{
Cross-validation of the American college of sports medicine's metabolic prediction equation for walking in older females
}

Debra Fegan

San Jose State University

Follow this and additional works at: https://scholarworks.sjsu.edu/etd_theses

\section{Recommended Citation}

Fegan, Debra, "Cross-validation of the American college of sports medicine's metabolic prediction equation for walking in older females" (1992). Master's Theses. 455.

DOI: https://doi.org/10.31979/etd.bk2t-ghft

https://scholarworks.sjsu.edu/etd_theses/455

This Thesis is brought to you for free and open access by the Master's Theses and Graduate Research at SJSU ScholarWorks. It has been accepted for inclusion in Master's Theses by an authorized administrator of SJSU ScholarWorks. For more information, please contact scholarworks@sjsu.edu. 


\section{INFORMATION TO USERS}

This manuscript has been reproduced from the microfilm master. UMI films the text directly from the original or copy submitted. Thus, some thesis and dissertation copies are in typewriter face, while others may be from any type of computer printer.

The quality of this reproduction is dependent upon the quality of the copy submitted. Broken or indistinct print, colored or poor quality illustrations and photographs, print bleedthrough, substandard margins, and improper alignment can adversely affect reproduction.

In the unlikely event that the author did not send UMI a complete manuscript and there are missing pages, these will be noted. Also, if unauthorized copyright material had to be removed, a note will indicate the deletion.

Oversize materials (e.g., maps, drawings, charts) are reproduced by sectioning the original, beginning at the upper left-hand corner and continuing from left to right in equal sections with small overlaps. Each original is also photographed in one exposure and is included in reduced form at the back of the book.

Photographs included in the original manuscript have been reproduced xerographically in this copy. Higher quality $6 "$ " 9 9" black and white photographic prints are available for any photographs or illustrations appearing in this copy for an additional charge. Contact UMI directly to order.

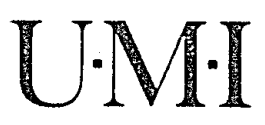



Order Number 1351026

Cross-validation of the American College of Sports Medicine's metabolic prediction equation for walking in older females

\author{
Fegan, Debra Lyn, M.A. \\ San Jose State University, 1992
}





\title{
CROSS-VALIDATION OF THE AMERICAN COLLEGE OF SPORTS MEDICINE'S METABOLIC PREDICTION EQUATION FOR WALKING IN OLDER FEMALES
}

\author{
A Thesis \\ Presented to \\ The Faculty of the Department of Human Performance \\ San Jose State University \\ In Partial Fulfillment \\ of the Requirements for the Degree \\ Master of Arts
}

By

Debra Fegan

December, 1992 
APPROVED FOR THE DEPARTMENT OF HUMAN PERFORMANCE

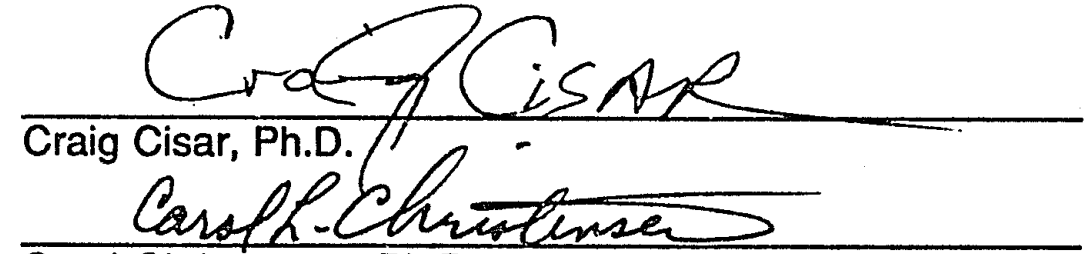

Carol Christensen, Ph.D

Haie Y. Luane

Gail Evans, Ph.D.

APPROVED FOR THE UNIVERSITY

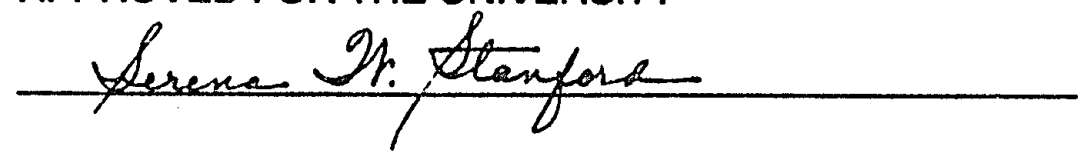




\section{ABSTRACT \\ CROSS-VALIDATION OF THE AMERICAN COLLEGE OF SPORTS MEDICINE'S METABOLIC PREDICTION EQUATION FOR WALKING IN OLDER FEMALES \\ by Debra Fegan}

The purpose of this study was to determine if the metabolic prediction equation for walking published by the American College of Sports Medicine (ACSM) could be used to accurately predict the oxygen uptake $\left(\mathrm{VO}_{2}\right)$ requirements in 13 females aged 55 to 78 years. The treadmill walking protocol consisted of four consecutive 6 minute phases beginning with level walking ( $0 \%$ grade) at 2.5 miles per hour ( $\mathrm{mph}$ ) (phase I), followed by $2.5 \mathrm{mph}$ at $3 \%$ grade (phase II), $3.5 \mathrm{mph}$ at $0 \%$ grade (phase III), and finally $3.5 \mathrm{mph}$ at $3 \%$ grade (phase IV). The mean $\mathrm{VO}_{2}$ values for the 5 th and 6 th minutes of each phase were used in the analysis of data. The equation is expected to underestimate the $\mathrm{VO}_{2}$ requirements of level walking by 15 to $20 \%$ and of walking up a $3 \%$ grade by 5 to $8 \%$. In this study, the prediction equation underestimated the mean $\mathrm{VO}_{2}$ requirements of the two level walking phases by 12 and $17 \%$. In the graded phases the equation overestimated the mean $\mathrm{VO}_{2}$ requirement by $5.5 \%$ in phase $\mathrm{II}$, and underestimated the mean $\mathrm{VO}_{2}$ requirement in phase IV by $4 \%$. The mean differences were significant $(\mathrm{p} \leq .05)$ for the $\mathrm{VO}_{2}$ requirements of level walking at 2.5 and $3.5 \mathrm{mph}$ in phase I and phase III.. The total errors ranged from 1.85 to $4.23 \mathrm{ml} \cdot \mathrm{kg}^{-1} \cdot \mathrm{min}^{-1}$ or appproximately 0.5 and1.2 METS. In conclusion, the equation can be used as a guidleline to estimate the $\mathrm{VO}_{2}$ requirements of walking in older females, although the potential ranges in error should be taken into account when the equation is used. 


\section{Acknowledgments}

I would like to express my gratitude and appreciation to the following people: Craig Cisar, committee chairman, for his ideas and support; Carol Christensen, committe member, for her guidance, support and sense of humor; Gail Evans, committe member, for her perspective and comments; Rich Schroeder and the personnel of DeAnza College Exercise Physiology Laboratory, especially Martha and Wendy for their time and willingness to help me with this project; Dr. John Greenleaf, Andrew Ertl and Alan Dearborn, who provided their time and support during the data collection process; my fellow graduate students and friends, and my Dad (George Fegan) for their efforts and encouragement, especially Donna Waugh Johnson, Scott Setterlund and Doug Moberg. A special thanks to the Fifty-Plus Runners Association and all of the subjects for their valuable cooperation and interest in the study, especially my Mom (Viola Fegan) who participated in the study and was always willing to help whenever necessary. Finally to my husband, Doug Meyer, who supported, encouraged and believed in me. 


\section{Table of Contents}

\begin{tabular}{lc} 
Abstract & page \\
Acknowledgements & iii \\
List of Tables & iv \\
CHAPTERI & \\
Introduction & 1 \\
Background for the Study & 1 \\
Purpose of the Study & 4 \\
Approach to the Problem & 4 \\
Statement of the Hypotheses & 4 \\
Delimitations & 5 \\
Limitations & 5 \\
Assumptions & 6 \\
Definition of Terms & 6 \\
CHAPTER II & \\
Introduction & 82 \\
Basis of Calorimetry & 81 \\
Development of the Prediction Equations & 11 \\
Use of the Prediction Equations & 19 \\
CHAPTER III & 21 \\
Introduction & 82 \\
Subjects & \\
Measurements and Methods & \\
\hline
\end{tabular}


Cardiovascular Fitness Test $\quad 22$

$\begin{array}{ll}\text { Height and Weight } & 24\end{array}$

Submaximal Exercise Protocol 24

Data Analysis $\quad 26$

\section{CHAPTER IV}

$\begin{array}{ll}\text { Introduction } & 27\end{array}$

$\begin{array}{ll}\text { Analysis of Data } & 27\end{array}$

Discussion of Results 31

$\begin{array}{ll}\text { Conclusions } & 34\end{array}$

Weaknesses of the Study $\quad 35$

Recommendations for Future Research $\quad 35$

$\begin{array}{ll}\text { References } & 37\end{array}$

$\begin{array}{ll}\text { Appendices } & 40\end{array}$ 


\section{List of Tables}

page

Table 1 Descriptive Characteristics of the Subjects 27

Table 2 Average Weekly Activity Level 28

Table 3 Comparison of Predicted $\mathrm{VO}_{2}$ to Actual $\mathrm{VO}_{2} \quad 30$

Table 4 Validation of Predicted Oxygen Consumption 30 


\section{CHAPTER I}

\section{Introduction}

This chapter is divided into several sections as follows: background for the study, statement of the problem, approach to the problem, statement of the hypotheses, delimitations, limitations, assumptions, and definition of terms.

\section{Background for the Study}

The efficiency or economy of the human body is determined by comparing the amount of energy input necessary to produce a given amount of work output (Fox, Bowers, \& Foss, 1988). Evaluating the energy requirements of the human body is important for a variety of different occupational, recreational, and medical reasons. Assessment of the energy requirements for labor intensive occupations is necessary to determine the minimal physical work capacity needed for the job. An endurance athlete needs to know the energy requirements of his or her event in order to adequately prepare. The reduced efficiency of an individual performing a given task enables physicians to diagnose certain medical disorders. The known energy requirements of physical activities allows for the development of proper exercise prescriptions for diseased and healihy populations.

The technique known as calorimetry is used to quantify the energy requirements of the human body while performing work. The technique is based on the principle of conservation of energy which states that energy can be transformed from one type to another, but the total energy of a system will remain constant (Consolazio, Johnson, \& Pecora, 1963). There are two types of calorimetry used in human research, direct and indirect. With direct calorimetry, 
the body's energy requirements are determined by measuring energy expenditure in the form of heat. Indirect calorimetry measures the body's oxygen utilization, or oxygen uptake rate, to determine it's energy requirements (Consolazio et al., 1963).

In the late 1800 's, Atwater and Benedict determined that the efficiency of the human body could be measured (Smith, 1922). Using a respiration calorimeter, they determined that the methods of direct and indirect calorimetry were in agreement and therefore indirect calorimetry could be used as a valid measure for assessing the body's energy requirements (Consolazio et al., 1963; Passmore \& Durnin, 1955; Smith, 1922). Indirect calorimetry involves less time and effort than direct calorimetry, therefore validating the use of oxygen uptake rate as a basis for measuring energy requirements was an important finding.

The need for an even more simplified method of accurately determining the body's energy requirements led to the development of numerous mathematical prediction equations. Since most basic research is performed in a laboratory environment, the prediction equations tend to be limited to tasks involving walking or running on a treadmill, stationary cycling or rowing on ergometers, or stair stepping. Numerous treadmill walking studies have been conducted in order to determine the effects of variables such as speed, grade, stride length, stride frequency, physical training, and body weight on the energy requirements of walking (Balke \& Ware, 1959; Coates \& Meade, 1960; Dill, 1965; Erickson, Simonson, Taylor, Alexander, \& Keys, 1946; Givoni \& Goldman, 1971; Ralston, 1958; Van Der Walt \& Wyndham, 1973; Workman \& Armstrong, 1963). Studies have also been conducted to dermine if age effects the energy 
requirements of the human body while walking, although few studies have used females or individuals over the age of 55 years (Bobbert, 1960; Grimby \& Soderholm, 1962; Mahadeva, Passmore and Woolf, 1953; Montoye, 1982; Montoye, Ayen, Nagle, \& Howley, 1985).

The studies conducted which used age as a variable in predicting the energy requirement of walking resulted in conflicting conclusions. Mahadeva et al. (1953) found that the energy requirement of level walking at $3.0 \mathrm{mph}$ could best be predicted from body weight alone. No significant increases in prediction precision could be obtained by taking age into account. Weight was also found to be the most important single factor governing the energy requirements of level and graded walking in a study conducted by Bobbert (1960), but in the discussion age, morphology, and training were ackowledged to be significant factors governing energy requirements. Grimby and Soderholm (1962) found the energy requirements of level walking to increase with age. Montoye (1982) found the energy requirements of graded walking to be higher in individuals over the age of 45 years. In contrast, Montoye et al. (1985) later found that age made no significant difference in the energy requirements of graded walking at $3.0 \mathrm{mph}$.

Many physiological changes obviously occur with aging. The decline of muscle mass, lung vital capacity, and physical work capacity (Astrand and Rodahl, 1986; Kenney, 1982;) with age would seem to indicate a decreased efficiency in work performance. This would imply that a greater amount of energy input would be required by an older individual to do a given level of work output. According to Montoye et al. (1985), the American College of Sports Medicine's (ACSM) prediction equation for the energy requirements of 
graded treadmill walking is based on previous studies conducted by Dill (1965) and Balke and Ware (1959). The subjects in the Dill (1965) study were three men between the ages of 23 and 42; those in the Balke and Ware (1959) study were military men between the ages of approximately 25 and 45 years. Whether this equation can be used to accurately predict the energy requirements of walking in an older female population has not been comprehensively researched.

\section{Purpose of the Study}

The purpose of this study was to validate the metabolic prediction equation for graded walking published by the American College of Sports Medicine in Guidelines for Exercise Testing and Prescription (1986) for a subject population of females 55 to 78 years of age.

\section{Approach to the Problem}

A sample population of 13 female subjects who were 55 to 78 years of age were studied to assess the actual oxygen uptake rate of walking $2.5 \mathrm{mph}$ at $0 \%$ and $3 \%$ grades, and $3.5 \mathrm{mph}$ at $0 \%$ and $3 \%$ grades, on a motor-driven treadmill. A statistical analysis was then conducted to determine if there were any significant differences between the actual oxygen uptake rate and the predicted oxygen uptake rate derived from the ACSM's metabolic equation.

\section{Statement of the Hypotheses}

1. There will be no difference in the actual oxygen uptake rate and the predicted oxygen uptake rate of walking at $2.5 \mathrm{mph}$ at a $0 \%$ grade.

2. There will be no difference in the actual oxygen uptake rate and the predicted oxygen uptake rate of walking at $2.5 \mathrm{mph}$ at a $3 \%$ grade. 
3. There will be no difference in the actual oxygen uptake rate and the predicted oxygen uptake rate of walking at $3.5 \mathrm{mph}$ at a $0 \%$ grade.

4. There will be no difference in the actual oxygen uptake rate and the predicted oxygen uptake rate of walking at $3.5 \mathrm{mph}$ at a $3 \%$ grade.

\section{Delimitations}

The study was delimited to 13 apparently healthy female volunteers, 55 to 78 years of age. The equation can be used with walking speeds between 1.9 and 3.7 miles per hour (American College of Sport Medicine [ACSM], 1986), but only the oxygen uptake rate of walking at 2.5 and $3.5 \mathrm{mph}$ at $0 \%$ and $3 \%$ grades were evaluated. The study was conducted in a laboratory environment. Based on criteria established by Montoye, Cunningham, Welch, and Epstein (1970), the subjects:

1) had no history of myocardial infarction, angina pectoris, congestive heart failure, or cerebrovascular accidents;

2) demonstrated normal resting electrocardiogram readings;

3) demonstrated a resting systolic blood pressure at or below $170 \mathrm{mmHg}$ and a diastolic pressure at or below $100 \mathrm{mmHg}$;

4) demonstrated negative (normal) cardiovascular fitness test results;

5) were not on insulin therapy;

6) were not on any antiarrhythmic or antiangina medication; and

7) were free of any disease or disabilities which would seriously impair walking.

\section{Limitations}

The subjects were all volunteers from the San Francisco bay area. The individual factors which were not controlled for in this study included: 
1) the subjects' present level of fitness;

2) the subjects' current activity level;

3) the subjects' previous athletic/fitness level;

4) the subjects' current nutritional status; and

5) the subjects' resting metabolic rate.

\section{Assumptions}

It was assumed that: 1) the subjects had achieved a steady state of exercise between the fifth and sixth minute of walking at each grade level; and 2), the resting level of oxygen uptake rate for each individual was the same and was equal to 3.5 milliliters of oxygen per kilogram of body weight per minute (ACSM, 1986).

\section{Definition of Terms}

Body Weight. The total weight of all body tissues expressed in kilograms.

Kilocalorie (kcal). A unit of heat used to express the energy value of food or the energy requirements of performing a given amount of work (Consolazio et al., 1963).

Mean Difference ( $\Delta$ ). A statistical term which is equal to the difference between the mean predicted value and the mean observed value.

Metabolic Equivalent (MET). A MET is a relative measure of the body's energy requirements. It is used to express the body's rate of energy expenditure while performing a given amount of work. It is a multiple of the resting oxygen uptake rate. One MET equals the oxygen uptake rate required of a seated individual at rest, which is approximately $3.5 \mathrm{ml} \cdot \mathrm{kg}^{-1} \cdot \mathrm{min}^{-1}$ (ACSM, 1986). 
Oxygen Uptake Rate $\left(\mathrm{VO}_{2}\right) . \mathrm{VO}_{2}$ is the rate at which the body utilizes oxygen from inspired air as it performs work. $\mathrm{VO}_{2}$ is expressed as milliliters of oxygen per kilogram of body weight per minute $\left(\mathrm{ml} \cdot \mathrm{kg}^{-1} \cdot \mathrm{min}^{-1}\right)$. It is used to measure the energy requirements of performing a given amount of work while the body is in a steady state (Astrand \& Rodahl, 1986).

Respiratory Exchange Ratio (R). $R$ is the ratio of the volume of carbon dioxide expired per minute to the volume of oxygen consumed per minute $\left(\mathrm{VCO}_{2} / \mathrm{NO}_{2}\right)$. It reflects the relative contribution of fat and carbohydrate to energy production. An $\mathrm{R}$ value equal to 0.70 indicates that fat is the energy source, 0.85 indicates the energy source is a mixture of $50 \%$ fat and $50 \%$ carbohydrate, and 1.00 indicates that carbohydrate is the energy source (Consolazio et al., 1963).

Standard Error of Estimate (SEE). A statistical term which represents the range in error between the predicted value and the actual value.

Steady State. It is the time period during which physiological functions remain at a constant (steady) value (Fox et al., 1988). In this study, it pertains to $\mathrm{VO}_{2}$; achievement of $\mathrm{VO}_{2}$ steady state will be assumed between the fifth and sixth minute of exercise.

Total Error (TE). A statistical term which accounts for the combined effect of the mean difference and the standard error of estimate. It represents the combined explained and unexplained variation between the predicted value and the actual value. It is calculated by taking the square root of the following formula:

$\left.T E=\left[\left(S_{\Delta}\right)^{2}(n-1)\right)+\left(\Delta n^{2} / n\right)\right] \div n(C . J$. Cisar, personal communication, September 1991). 


\title{
CHAPTER II
}

\section{REVIEW OF LITERATURE}

\author{
Introduction
}

This chapter is divided into three sections, including basis of calorimetry, development of the prediction equations, and use of the prediction equations.

\section{Basis of Calorimetry}

Calorimetry is a technique used to quantify the human energy requirements of performing work. Energy is defined as the capacity to do work, and has the ability to take on many different forms (Fox et al., 1988). Heat is one of the common forms of energy, and like work, represents a transference of energy (Fox et al., 1988). Work is done whenever energy is transferred from one object to another. The human body transforms the chemical energy derived from the metabolism of foodstuffs into heat and/or mechanical energy when the body is performing work. Calorimetry is based on the first law of thermodynamics and the principle of conservation of energy (Fox et al., 1988). This principle states that, "The total energy of a system is neither increased nor decreased in any process. Energy can be transformed from one kind to another, but the total amount remains constant" (Giancoli, 1980). Therefore, the energy value (caloric value) of the foodstuffs metabolized should be equivalent to the amount of heat liberated by the body (Fox et al., 1988).

There are two types of calorimetry used in human research, direct and indirect. Direct calorimetry is based on the above concept and assesses the 
body's energy requirements by measuring energy expenditure in the form of heat (Consolazio et al., 1963). Indirect calorimetry is based on the known proportionality between the oxygen utilized $\left(\mathrm{VO}_{2}\right)$ or carbon dioxide produced $\left(\mathrm{VCO}_{2}\right)$ and the total energy requirements of the body to perform a given amount of work (Consolazio et al., 1963). The amount of oxygen consumed or carbon dioxide produced during rest or exercise can be expressed in terms of heat equivalents (kilocalories). Since the heat produced varies with the foodstuff metabolized, it becomes necessary to know the type of food being used as fuel in order to express oxygen consumption in terms of heat equivalents. For example, the combustion of 1.0 liter of oxygen produces 5.05 kilocalories of heat using carbohydrates as a fuel, 4.74 kilocalories of heat with fat, and 4.46 kilocalories of heat with protein (Consolazio et al., 1963).

Determination of the foodstuff metabolized is possible because the proportion of the oxygen utilized to the carbon dioxide produced also varies with the type of food metabolized. The ratio of the volume of carbon dioxide produced to the oxygen utilized per minute is called the respiratory exchange ratio $(R)$. For example, an $R$ ratio of 0.70 indicates that fat is the fuel source, 0.85 is a mixture of $50 \%$ fat and $50 \%$ carbohydrate, and 1.00 indicates that only carbohydrate is being used as the fuel source (Consolazio et al., 1963). Indirect calorimetry is also known as respiratory calorimetry.

Repiratory calorimetry is performed by either the open-circuit method or the closed-circuit method. In the open-circuit method, the subject is allowed to breathe room air, while the expired air is collected for volumetric measurement. The gas volume is then corrected for environmental conditions and is analyzed for its oxygen and carbon dioxide content in order to determine the oxygen 
utilization and carbon dioxide production of the body (Consolazio et al., 1963). In the closed-circuit method the subject breathes through a closed system which initially contains a known amount of oxygen. The oxygen utilized by the body is then measured by the decrease in oxygen in the closed system (Consolazio, et al., 1963). Once oxygen utilization is determined, the body's energy expenditure can be calculated and expressed in terms of kilocalories (kcals).

It is conventional to express energy requirements in terms of power, which is equivalent to the rate of energy expenditure that occurs in response to a given work output. A metabolic term for the rate of energy expenditure is the MET (metabolic equivalent). One MET equals the resting oxygen uptake rate ( $\mathrm{VO}_{2}$ rest) and represents the approximate rate of oxygen required per minute under quiet resting conditions (ACSM, 1986).

Research conducted in the late 1800's and early 1900's determined that indirect calorimetry was a valid method for determining the rate of energy expenditure (Consolazio et al., 1963; Passmore \& Durnin; 1955; Smith, 1922). In the original experiments, energy intake was shown to balance with energy expenditure, thereby proving the validity and reliability of the use of calorimetry to determine energy requirements based on the law of conservation of energy (Consolazio et al., 1963). The indirect calorimetry method of using rates of oxygen uptake as the basis for measuring energy expenditure was later proven to be as accurate as the direct method (Consolazio et al., 1963; Passmore \& Durnin; 1955; Smith, 1922). This was an important finding due to the difficulty of performing direct calorimetry and the relative ease of performing indirect calorimetry. 


\section{Development of the Prediction Equations}

The early work of Atwater and Benedict enabled the determination of the body's energy requirements during muscular exercise (Consolazio et al., 1963; Passmore \& Durnin; 1955; Smith, 1922). The results of their experiments utilizing the respiration calorimeter demonstrated that the body's energy requirements could be determined by measuring energy expenditure. Further investigation led to the discovery that indirect calorimetry could also be used as a valid means for measuring energy expenditure (Consolazio, et al., 1963; Passmore \& Durnin, 1955; Smith, 1922). Numerous treadmill walking studies have been conducted in order to determine the effects of variables such as speed, grade, stride length, stride frequency, physical training, and body weight on the energy requirements of walking (Balke \& Ware, 1959; Coates \& Meade, 1960; Dill, 1965; Erickson et al., 1946; Givoni \& Goldman, 1971; Ralston, 1958; Van Der Walt \& Wyndham, 1973; Workman \& Armstrong, 1963). Equations were developed in an attempt to accurately and reliably predict the effects of these factors. Studies have also been conducted to dermine if age effects the energy requirements of the human body while walking, although few studies have used females or individuals over the age of 55 years (Bobbert, 1960; Grimby \& Soderholm, 1962; Mahadeva et al., 1953; Montoye, 1982; Montoye et al., 1985).

Some of the earliest studies which measured energy expenditure during treadmill walking concluded that energy expenditure was dependent on the magnitude of the speed and grade at which one walked (Erickson et al., 1946). The oxygen uptake per kilogram of body weight was measured and shown to increase linearly with increasing speed and grade. It was also shown that net 
efficiency, calculated from the caloric equivalent of the absolute amount of body lift divided by the difference between the energy expenditure of graded and horizontal walking, decreased at the lowest and highest speeds. Therefore, the greatest efficiency was seen at the middle speeds of 3.0 and 3.5 miles per hour (Erickson et al., 1946).

A study conducted with 50 volunteers between the ages of 13 and 79 years reported that energy expenditure during stepping or walking was directly proportional to body weight. No significant increases in prediction precision were obtained by taking height, age, sex, race, body surface area, diet or resting metabolism into account (Mahadeva et al., 1953). The regression equation developed therefore used weight as the only significant predictor of energy expenditure.

A longitudinal case study conducted on one man from age 41 to 66 years revealed that the efficiency of running declined greatly with age (Dill, Horvath, \& Craig, 1958). His oxygen uptake rate for running at a speed of 5.5 miles per hour increased from 29.4 at age 41 to $35 \mathrm{ml} \cdot \mathrm{kg}^{-1} \cdot \mathrm{min}^{-1}$ at age 66 . This might not be a realistic comparison to the previous studies because the speed was 5.5 miles per hour and running has been shown to utilize more total energy than walking (Thomas \& Londeree, 1989). The results become even more complicated because the individual experienced a $10 \%$ increase in body weight over the 25 year period. The individual's metabolic efficiency declined with age, but it is impossible to determine if the cause was related to aging or a change in lifestyle.

Ralston (1958) set out with the purpose of establishing a useful mathematical relationship between energy expenditure and speed. The study 
was conducted with 19 males and females between the ages of 22 and 51 years. Oxygen uptake rate was measured while the subjects walked on a track at speeds varying between approximately 1.0 and 3.6 miles per hour. The findings revealed that during level walking, the energy expenditure could be expressed as a linear function of the square of the speed, though body size must be taken into account for the relationship to have general significance.

The Guidelines for Exercise Testing and Prescription (ACSM,1986), a publication of the American College of Sports Medicine, contains an equation for estimating the steady-state oxygen requirements of graded treadmill walking. According to Montoye et al. (1985), the oxygen cost of one kilogrammeter of vertical work was based on a study conducted by Balke and Ware (1959) and later validated by Nagle, Balke and Naughton (1965). Balke and Ware (1959) conducted the study with 500 male Air Force personnel between the ages of approximately 25 and 45 years. The subjects oxygen uptake rate were measured as they walked on a motor driven treadmill at a speed of 3.3 miles per hour and $0 \%$ grade. The workload was increased every minute by elevating the treadmill grade $1 \%$. Speed was held constant. The results revealed a small difference in the efficiency of walking between individuals, and the well established correlation between work intensity and oxygen uptake per kilogram of body mass. The study demonstrated that an individual's aerobic work capacity was far more affected by sedentary living habits than by age.

The purpose of the study conducted by Bobbert (1960) was to develop a general equation which related the energy expenditure of treadmill walking to speed and grade. The equation was derived from the study of two male subjects, aged 25 years, walking at speeds ranging approximately between 1.3 
and 4.3 miles per hour and grades of 0,8 and 12 degrees. The outcome demonstrated that energy expenditure increased in a curvilinear manner with speed and grade. Since weight was known to influence the energy expenditure of walking the results were reported in calories per kilogram of body weight per minute.

In an effort to improve the precision of previously developed prediction equations, Cotes and Meade (1960) investigated the possible effect of variables such as anthropometry, vertical trunk oscillation, and step frequency on the energy expenditure of treadmill walking. The investigation involved eleven young male subjects walking on a treadmill at speeds varying from 1.0 to 4.0 miles per hour. The results indicated that energy expenditure was highly correlated with both lift work and the square of the walking velocity.

In a study conducted by Grimby and Soderholm (1962), oxygen uptake rate during walking was found to increase with age. Three age groups were studied: two groups consisted of firemen between the ages of 21 and 45 years, and an older group was comprised of industrial workers between the ages of 55 and 65 years. The subjects performed alternately on a stationary bicycle and a treadmill, with a minimum of a 5-6 minute rest period between each work period. The work loads on the bicycle were 300 and 600 kilopondmeters which elicited approximately the same energy expenditure as level walking on the treadmill at speeds of $4.5 \mathrm{~km} / \mathrm{hr}(2.7 \mathrm{mph})$ and $6 \mathrm{~km} / \mathrm{hr}(3.6 \mathrm{mph})$. The results revealed that oxygen uptake rate was equivalent for the different age groups in cycling, but increased with age in walking.

Workman and Armstrong (1963) developed an equation that predicted the oxygen uptake rate per minute to be equal to the product of oxygen 
consumption per step and the number of steps per minute. Since stride length and stride frequency appear to be self chosen in order to minimize energy expenditure, this equation was only relevent when energy conservation was the prime consideration. For example this equation would not accurately predict the energy expenditure of a fashion model's walk down the runway (Workman \& Armstrong, 1963). For the same reasons, untrained individuals or "poor" walkers would also not be expected to fit this equation well.

Dill (1965) later conducted a study to determine the energy requirements of horizontal and graded walking and running on a treadmill. The subjects consisted of two 23 year old men and the author whose age was 42 years. The results confirmed earlier findings that oxygen uptake rate increased linearly with increasing speeds of walking. The oxygen requirment per unit of horizontal work used in the ACSM's metabolic equation for walking was based on this study (Montoye et al., 1985). For horizontal walking at $1 \mathrm{~m} \cdot \mathrm{min}^{-1}$, Dill (1965) measured the net oxygen requirment to be about $0.1 \mathrm{ml} \cdot \mathrm{kg}^{-1} \cdot \mathrm{min}^{-1}$. This estimate was validated by comparing it to data in the literature. The literature reviewed showed values for the unit oxygen requirment of horizontal treadmill walking to range from .094 to $.154 \mathrm{ml} \cdot \mathrm{kg}^{-1} \cdot \mathrm{min}^{-1}$.

Givoni and Goldman (1971) developed a prediction equation which they stated was valid for walking speeds from approximately 1.5 to 5.4 miles per hour with grades up to $25 \%$. The results confirmed previous findings that the energy requirement of walking increased progressively with increases in speed, grade, and body weight. The slope of the rise increased with increasing speed, and at a given speed, the effect of grads is essentially linear. The metabolic cost of walking was also linearly related to the weight of the body. The 
prediction formula also included coefficients for the effect of terrain and external load. The energy requirement of walking increased when walking on surfaces other than a treadmill and when an external load was carried away from the center of gravity of the body. The authors also reported that when the product of the load carried and the speed of walking exceeded a certain value, the work efficiency decreased.

As in previous studies, Van Der Walt and Wyndham (1973) determined that body mass and speed are the most important determinants of energy expenditure during horizontal treadmill walking at speeds ranging from 1.9 to 4.8 miles per hour. Their equation expressed the oxygen uptake rate $(1 / \mathrm{min})$ of walking at a given speed to be directly proportional to body mass. Investigation of the influence of pace length and stride frequency revealed that they were not important factors in determining the energy requirment of treadmill walking.

A more recent study using direct calorimetry to determine the energy requirment of walking was performed using ten young, healthy males and females (Webb, Saris, Schoffelen, Van Ingen Schenau, \& Ten Hoor, 1988). The study concluded that the energy requirment of walking was mainly dependent on the walking speed and was not influenced by other forces that affect walking intensity. The work done during level walking was concluded to be the result of the interaction between the foot and the ground.

A study conducted by Montoye (1982) used one thousand fifty-eight men between the ages of 10 and 69 years to determine the age-related physiological responses to graded treadmill walking. The exercise test consisted of walking on a treadmill at 2.0 or 3.0 miles per hour at a $0 \%$ grade; the grade was then increased $3 \%$ every three minutes while speed was 
maintained. The results revealed little age related differences in the oxygen uptake rate of graded treadmill walking between individuals 20 to 45 years of age. Beyond the age of 45 years, there was a slight, although statistically significant increase in oxygen uptake rate that represented a small decrease in the efficiency of walking. Montoye (1982) reviewed previous studies that reported no age related differences in oxygen uptake rate among adults walking at submaximal workloads. He determined that the small increase in oxygen uptake rate observed in his study would not have been detected as significant in the previous studies due to their smaller sample sizes. Montoye (1982) also observed a higher respiratory exchange ratio and blood lactate concentration at a given submaximal workload in the older subjects, suggesting an increased reliance on anaerobic energy systems. The ventilation rate (VE), carbon dioxide production, ventilatory equivalent $(\mathrm{VENO} 2)$, and tidal volume were also observed to be higher in the older subjects.

Montoye et al. (1985) conducted a validation study of the American College of Sports Medicine's metabolic equation for graded treadmill walking using males between the ages of 10 and 69 years. The subjects walked at one speed of 3.0 miles per hour and grades ranging from $0 \%$ to $18 \%$. The results revealed that the equation estimated the oxygen requirement of graded walking at 3.0 miles per hour at most grades fairly accurately. However, the equation underestimated the $\mathrm{VO}_{2}$ requirement of horizontal walking and walking at a $3 \%$ grade. For horizontal walking the mean error was approximately 3 to 4 $\mathrm{ml} \cdot \mathrm{kg}^{-1} \cdot \mathrm{min}^{-1}$. At a $3 \%$ grade, the equation underestimated $\mathrm{VO}_{2}$ by approximately $1 \mathrm{ml}^{\mathrm{kg}}-1 \cdot \mathrm{min}^{-1}$. The standard error of estimate of the equation 
for horizontal walking in the 50 to 54 year old age group was $5.6 \mathrm{ml} \cdot \mathrm{kg}^{-1} \cdot \mathrm{min}^{-1}$ and $2.7 \mathrm{ml} \cdot \mathrm{kg}^{-1} \cdot \mathrm{min}^{-1}$ for walking at a $3 \%$ grade.

In summary, many equations have been developed in order to simply and accurately predict the oxygen uptake rate (energy requirement) of walking. The equations developed have used some of the following predictors as a means of assessing the oxygen uptake rate of treadmill walking: speed, grade, terrain, stride frequency, stride length, physical training, external load and body weight. The metabolic equation published in Guidelines for Exercise Testing and Prescription (ACSM, 1986), is one that is extensively used as it is the basic text for certification by the American College of Sports Medicine. The ACSM prediction equation is essentially made up of three components added together: a horizontal component, which is the speed of walking multiplied by a unit $\mathrm{VO}_{2}$ cost €qual to $0.1 \mathrm{ml} \mathrm{kg}^{-1} \cdot \mathrm{min}^{-1}$; a vertical component which equals the speed of walking multiplied by the grade, multiplied by a unit $\mathrm{VO}_{2}$ cost equal to 1.8 $\mathrm{ml} \cdot \mathrm{kg}^{-1} \cdot \mathrm{min}^{-1}$; and a resting $\mathrm{VO}_{2}$ component which equals $3.5 \mathrm{ml} \cdot \mathrm{kg}^{-1} \cdot \mathrm{min}^{-1}$. A simplified version of the formula is as follows:

$\mathrm{VO}_{2}\left(\mathrm{ml} \cdot \mathrm{kg}^{-1} \cdot \mathrm{min}^{-1}\right)=[$ speed $\times 0.1]+[$ grade $\times$ speed $\times 1.8]+[3.5]$

The unit horizontal and vertical $\mathrm{VO}_{2}$ costs were determined in studies conducted by Dill (1965) and Balke and Ware (1959). The resting VO2 is assumed to be $3.5 \mathrm{ml} \cdot \mathrm{kg}^{-1} \cdot \mathrm{min}^{-1}$ which is equivalent to $1 \mathrm{MET}$. Dill obtained the 0.1 value by subtracting observed or estimated resting $\mathrm{VO}_{2}$ from measured gross $\mathrm{VO}_{2}$ in three male subjects, then divided the net $\mathrm{VO}_{2}$ by speed and body weight to obtain the unit $\mathrm{VO}_{2}$ cost of horizontal walking. This value indicates 
that for every meter per minute (unit) increase in the horizontal speed of walking, the energy requirement of walking increases by $0.1 \mathrm{ml} \cdot \mathrm{kg}^{-1} \cdot \mathrm{min}^{-1}$. The derivation of the 1.8 value in the vertical component is not clear from Examination of the Balke and Ware (1959) study. The 1.8 value indicates that for every 1 meter-kilogram of vertical work performed there was an additional energy requirement of $1.8 \mathrm{ml} \cdot \mathrm{kg}^{-1} \cdot \mathrm{min}^{-1}$. The 1.8 value was later validated in a study conducted by Nagle et al. (1965).

\section{Use of the Prediction Equations}

Measurement of oxygen uptake rate for determining energy expenditure (indirect calorimetry) may be desirable, but it may be impractical or unavailable in some situations. When this is the case, estimates of oxygen uptake rate during steady-state exercise can be made. These estimates are based on equations which relate mechanical measures of work rates to their metabolic equivalents (ACSM, 1986). According to the American College of Sports Medicine, these equations are typically used in clinical settings to estimate the metabolic cost (MET) of exercise on a treadmill or cycle ergometer. The estimated METs can then be used as guidelines for exercise prescription or as a means for evaluating progress in an exercise program.

Tables of MET values have been developed to provide means and ranges of the estimated MET requirements for recreational or industrial activities. These tables are used in occupational settings, particularly in labor intensive industries, for the assessment of a disability, the ability of a worker to carry on in his or her job, or for the assessment of the suitability of an individual's physical fitness for a given occupation (Jones, 1988). 
If metabolic prediction equations are used in clinical settings for exercise prescription, rehabilitation progress, and employment suitability, an elderly individual may be at a severe disadvantage if the equations do not give valid estimates of energy expenditure for individuals in their age group. Also, the ACSM equation may not be an accurate predictor of the energy cost of walking for adult females, since the derivation of the metabolic equation was based on data collected on adult males. Hence, a study to determine if the equation is valid for females over 55 years of age was needed. 


\section{CHAPTER III}

\section{METHODS}

Introduction

This chapter contains information about the subjects, the measurements and methods, the experimental design and the data analysis. The experimental design consists of the cardiovascular fitness test and the submaximal exercise protocol.

\section{Subjects}

The subjects in this study were 13 apparently healthy female volunteers ranging in age from 55 to 78 years. All participants were required to read and sign an informed consent form (Appendix A), approved by the Human Subjects Institutional Review Board of San Jose State University, and complete a health screening prior to their participation in the study.

The health screening included a comprehensive health history questionnaire (Appendix B) and a cardiovascular fitness test. The health history questionnaire contained questions which allowed for the assessment of the subject's past and present physical activity levels. The cardiovascular fitness test was conducted in the Exercise Physiology Laboratory at DeAnza College. Written approval was obtained from the subject's family physician prior to taking the cardiovascular fitness test (Appendix $\mathrm{C}$ ). The fitness test was observed and evaluated by a physician affiliated with DeAnza's Exercise Physiology Laboratory. Subjects were excluded from participating in the study based on the following medical criteria: 1) an abnormal resting electrocardiogram reading, 2) a resting systolic blood pressure exceeding $170 \mathrm{mmHg}, 3$ ) a 
resting diastolic blood pressure exceeding $100 \mathrm{mmHg}$, 4) a positive cardiovascular fitness test, 5) any history of myocardial infarction, angina pectoris, congestive heart failure, or cerebrovascular accidents, 6) taking insulin therapy, 7) taking any antiarrhythmic or antiangina medications, or 8) having any disease or disabilities which would seriously impair walking (Montoye et al., 1970).

\section{Measurements and Methods}

The study required two testing sessions occurring within two weeks of each other. The first session consisted of a cardiovascular fitness test performed at DeAnza College Exercise Physiology Laboratory. The second session was conducted at the San Jose State University Exercise Physiology Laboratory and included the following assessments: 1) height and weight, 2) resting electrocardiogram, 3) resting blood pressure, and 4) submaximal oxygen uptake rate while walking on a motor driven treadmill. The subjects reported to the laboratories on a scheduled time and day. The subjects had been previously instructed not to eat, drink, or smoke for two to three hours prior to testing time. They were also informed of the appropriate clothing to wear for exercise.

\section{Cardiovascular Fitness Test}

The cardiovascular fitness test was conducted in the Exercise Physiology Laboratory at DeAnza College in Cupertino. The results of the test were used to assess the subject's cardiovascular fitness for health screening purposes and to rank the subject's fitness levels from high to low based on their peak oxygen uptake rate. Peak oxygen uptake rate and peak heart rate were determined using a graded exercise protocol on a motorized treadmill. A Modified Bruce 
protocol (Bruce, 1971) was used which consisted of increases in the speed and elevation of the treadmill every 3 minutes until voluntary exhaustion. The first stage of the protocol started at $1.7 \mathrm{mph}$ and increased $.8 \mathrm{mph}$ each stage. The elevation started at $10 \%$ and increased $2 \%$ each stage. The test was terminated if any of the following situations occurred during testing: 1) a signal from the subject indicating that she wished to stop the test, 2) failure of the heart rate to increase with increasing workloads, 3) any significant drop (10 $\mathrm{mm} \mathrm{Hg})$ of systolic blood pressure or failure of the systolic blood pressure to rise with an increase in exercise workload, 5) a blood pressure reading greater than $250 / 120 \mathrm{~mm} \mathrm{Hg}, 6$ ) pain or fatigue as indicated by decreasing coordination or pallor, 7) dizziness or faintness, 8) any abnormalities on the ECG reading, or 9) equipment failure (ACSM, 1986). Reasons the subjects may have wished to stop the test included pain, anxiety, or the perception of any unusual sensation or feeling not normally experienced during exercise.

Peak oxygen uptake rate was determined using an open-circuit respiratory system. The subject inhaled room air through a Hans-Rudolph respiratory valve which was supported by headgear. The volume of inspired air was measured by a pneumotachometer (Sensormedics VMM2) and samples of dried expired air were withdrawn from a mixing chamber and analyzed for oxygen and carbon dioxide content via an Apple II E computer based system which interfaced with electronic gas analyzers (Sensormedics OM11 and Beckman LB-2). The analyzers were calibrated before and periodically during each test with a standard gas sample. Data for inspired air and expired air were collected every minute of the test. 
The subject's electrocardiogram (EKG) was continuously monitored on a Quinton Model 630A electrocardiograph. A 5-lead electrode placement was used to obtain heartrate and EKG readings in leads II, AVF and V5. The electrocardiogram was printed out for the last 10 seconds of every minute of the test at a speed of $25 \mathrm{~mm} / \mathrm{sec}$. Blood pressure was monitored every minute of the test. Following completion of the test, subjects were instructed to continue walking at a reduced speed and grade until heart rate and blood pressure returned to near resting values.

\section{Height and Weight}

Height was measured to the nearest $0.1 \mathrm{~cm}$ using a wall scale with a Broca plane. A calibrated beam-type balance scale was used to assess total body weight to the nearest 0.1 kilogram. The subjects were dressed in light cotton clothing, excluding shoes.

\section{Submaximal Exercise Protocol}

Heart rate (HR), blood pressure (BP), and electrocardiogram (ECG) were evaluated while the subjects were sitting at rest prior to walking on the treadmill. The subjects were allowed to warm-up for approximately four minutes at a speed of less than $2.5 \mathrm{mph}$ and a $0 \%$ grade. The test consisted of four consecutive six minute phases as follows: 1) walking at $2.5 \mathrm{mph}$ at a $0 \%$ grade, 2) walking at $2.5 \mathrm{mph}$ at a $3 \%$ grade, 3) walking at $3.5 \mathrm{mph}$ at a $0 \%$ grade, and 4) walking at $3.5 \mathrm{mph}$ at a $3 \%$ grade. Continuous measures of $\mathrm{VO}_{2}, \mathrm{HR}$, and ECG were maintained, though for this study only the mean $\mathrm{VO}_{2}$ values for the 5th and 6th minutes of exercise at each workload were used in the data analysis. The test was discontinued when any of the following signs were present: dizziness or faintness, lack of coordination, pain, fatigue, staggering, 
pallor, abnormal ECG readings, failure of the ECG equipment, blood pressure readings greater than $250 / 120 \mathrm{~mm} \mathrm{Hg}$, a drop in systolic blood pressure of 10 $\mathrm{mm} \mathrm{Hg}$ or more, failure of the systolic blood pressure to rise with increasing workloads, or when the subject motioned that she was exhausted and/or uncomfortable with continuing due to pain, anxiety or the perception of any unusual sensation or feeling not normally experienced during exercise. If the activity was not terminated for one of the above reasons, the end-point of the activity was when the subject's heart rate reached $85 \%$ of her age predicted maximum heart rate (ACSM, 1986), or when all data had been collected. A cool-down period followed the testing. The cool-down continued until the heart rate and blood pressure returned to near resting values. Post exercise ECG and blood pressure readings were also obtained.

Open circuit calorimetry was used to obtain the oxygen uptake rate measurements. The subject was fitted with headgear which supported a HansRudolph respiratory valve and mouthpiece. Inhaled air passed through a Parkinson-Cowan CD-4 dry test meter and then into the respiratory valve. An on-line potentiometer was used to record the volume of inspired air. The expired air passed over a dessicated column to remove water vapor and then passed through a mixing chamber into the Wilmore-Costill Spinner Valve system and finally into analyzers. A Beckman LB-2 Medical Gas Analyzer and an Applied Electrochemistry S-3A Oxygen Analyzer were used to determine the oxygen and carbon dioxide concentrations in the expired air. The outputs of the analyzers were sent to an Apple II computer which calculated the respiratory ratio $(\mathrm{R})$, oxygen uptake rate $\left(\mathrm{VO}_{2}\right)$, carbon dioxide production rate $\left(\mathrm{VCO}_{2}\right)$, and expired ventilation rate (VE). The data were collected during each minute of the 
test. The analyzers were calibrated before and periodically during each test with a standard gas sample.

A standard CM-5 electrode lead placement was used to continuously monitor electrocardiogram (ECG) readings on a Quinton Model 633 electrocardiograph. The ECG was printed for the last ten seconds of every minute of the test at a speed of $25 \mathrm{~mm} / \mathrm{sec}$.

\section{Data Analysis}

Descriptive statistics were used to describe overall age, physical activity levels, height, weight, maximal oxygen uptake rate, and the submaximal oxygen uptake rates measured in each of the four phases of the submaximal exercise protocol. Repeated measures one-way analyses of variance were used to determine the differences between the actual versus the predicted oxygen uptake rates of $2.5 \mathrm{mph}$ treadmill walking at 0 and $3 \%$ grades, and $3.5 \mathrm{mph}$ treadmill walking at 0 and $3 \%$ grades. The analyses were based on calculation of the mean errors, the intraclass correlation coefficients $(R)$, the standard error of the estimates (SEE), and the total errors (TE) associated with the prediction equation for each of the exercise phases. The SPSSX computer program and Apple II statistical program were used for the statistical analysis of the data. 


\section{CHAPTER IV}

Results and Discussion

Introduction

This chapter includes the analysis of data, discussion of results, conclusions, weaknesses of the study, and recommendations for future research.

\section{Analysis of Data}

Table 1 shows the descriptive characteristics for the overall group of subjects. The mean $( \pm S D$ ) age, height and weight of the subjects were 65.85 $( \pm 7.25) \mathrm{yr}, 164.14( \pm 6.92) \mathrm{cm}$, and $59.72( \pm 7.78) \mathrm{kg}$, respectively. The mean $( \pm S D)$ peak oxygen uptake rate of the subjects was $31.38( \pm 8.38)$ $\mathrm{ml} \cdot \mathrm{kg}^{-1} \cdot \mathrm{min}^{-1}$.

Table I

Descriptive Characteristics of the Subjects $(n=13)$.

$\begin{array}{lll}\text { Characteristic } & M( \pm S D) & \text { Range }\end{array}$

\begin{tabular}{lrr} 
Age $(\mathrm{yr})$ & $65.85 \pm 7.25$ & $55.83-78.83$ \\
Height $(\mathrm{cm})$ & $164.14 \pm 6.92$ & $155.00-176.30$ \\
Weight $(\mathrm{kg})$ & $59.72 \pm 7.78$ & $44.60-75.80$ \\
Peak VO $2\left(\mathrm{ml} \cdot \mathrm{kg}^{-1} \cdot \mathrm{min}^{-1}\right)$ & $31.39 \pm 8.38$ & $16.00-45.00$ \\
\hline
\end{tabular}


Table 2 presents the average activity level of the subjects and categorizes their fitness level based on age and maximal oxygen uptake rate values (Shvartz \& Reibold, 1990). The majority of the subjects were classified in the good to excellent fitness category. Running was the activity performed three to five times per week by the four subjects who classified themselves as heavy exercisers. The activity of the seven subjects who performed moderate exercise three to five times per week was either running or aerobic dance classes. The two subjects who performed light exercise one to two times per week either walked or attended aerobic dance classes for their exercise activity.

Table 2

Average Weekly Activity Level.

\begin{tabular}{clcl}
\hline Days per week & Activity level & Subjects & Fitness category \\
\hline $3-5$ & Heavy & 4 & Good - Excellent \\
$3-5$ & Moderate & 7 & Good - Excellent \\
$1-2$ & Light & 2 & Poor - Average \\
\hline
\end{tabular}

Table 3 compares the predicted oxygen uptake rate values to the actual oxygen uptake rate values in each of the four phases of the treadmill protocol. In phase I of the treadmill protocol the subjects walked at $2.5 \mathrm{mph}$ at a $0 \%$ grade, phase II was $2.5 \mathrm{mph}$ and $3 \%$ grade, phase III was $3.5 \mathrm{mph}$ and $0 \%$ grade, and finally phase IV was $3.5 \mathrm{mph}$ and a $3 \%$ grade. The actual mean 
oxygen uptake rate value $( \pm S D)$ for phase I was $11.52( \pm 1.79) \mathrm{ml} \cdot \mathrm{kg}^{-1} \cdot \mathrm{min}^{-1}$ compared to the predicted oxygen uptake rate value of $10.17 \mathrm{ml} \cdot \mathrm{kg}^{-1} \cdot \mathrm{min}^{-1}$, in phase II the actual mean value was $13.02( \pm 1.58) \mathrm{ml} \cdot \mathrm{kg}^{-1} \cdot \mathrm{min}^{-1}$ versus the predicted value of $13.77 \mathrm{ml} \cdot \mathrm{kg}^{-1} \cdot \mathrm{min}^{-1}$, actual mean value in phase III was $15.46( \pm 2.12) \mathrm{ml}^{\prime} \mathrm{kg}^{-1} \cdot \mathrm{min}^{-1}$ versus $12.83 \mathrm{ml} \cdot \mathrm{kg}^{-1} \cdot \mathrm{min}^{-1}$, and in phase IV the actual mean value was $18.56( \pm 3.0) \mathrm{ml} \cdot \mathrm{kg}^{-1} \cdot \mathrm{min}^{-1}$ versus $17.87 \mathrm{ml} \cdot \mathrm{kg}^{-1} \cdot \mathrm{min}^{-1}$. The prediction equation is expected to underestimate level walking by 15 to $20 \%$ and by 5 to $8 \%$ with walking up a $3 \%$ grade (ACSM, 1986). In this study the prediction equation underestimated the mean oxygen uptake rate in the level walking phases, I and III, by $12 \%$ and $17 \%$. In the $3 \%$ graded phases, the equation overestimated the mean oxygen uptake rate by $5.5 \%$ in phase II, and underestimated the mean oxygen uptake rate by $4 \%$ in phase IV. The differences were significant ( $\mathrm{D} \leq .05$ ) for level walking in phase I and phase III.

Table 4 summarizes the comparison between the actual oxygen consumption values and the predicted oxygen consumption values derived from the American College of Sports Medicine prediction equation. Repeated measures one-way analyses of variance were used to determine the intraclass correlation coefficients $(R)$ and examine the mean errors between the actual versus predicted oxygen uptake rate. The absolute value of the mean errors ranged from 0.69 to $2.63 \mathrm{ml} \cdot \mathrm{kg}^{-1} \cdot \mathrm{min}^{-1}$. The mean error was significant ( $\mathrm{g} \leq .05$ ) in the level phases of the treadmill protocol (phases I and III). Phases II and IV, the graded phases, resulted in nonsignificant mean errors. The intraclass correlation coefficients were moderate to high ranging from $R=.66$ to $R=.94$. The standard error of the estimates (SEE) ranged from 0.76 to 2.22 $\mathrm{ml} \cdot \mathrm{kg}^{-1} \cdot \mathrm{min}^{-1}$ for the actual oxygen uptake rate values. Combining the effects 
Table 3

Comparison of Predicted VO2 $\left(\mathrm{ml} \cdot \mathrm{kg}^{-1} \cdot \mathrm{min}^{-1} \mathrm{~L}\right.$ to Actual VO2. $\left(\mathrm{ml} \cdot \mathrm{kg}^{-1} \cdot \mathrm{min}^{-1}\right)$

\begin{tabular}{lccccc}
\hline Phase & Speed/Grade & $\begin{array}{c}\text { Predicted } \\
\mathrm{VO}_{2}\end{array}$ & $\begin{array}{c}\text { Actual } \\
\mathrm{VO}_{2}\end{array}$ & $\begin{array}{c}\text { Predicted } \\
\text { Mean Error } \\
(\mathrm{M}( \pm \mathrm{SD})\end{array}$ & $\begin{array}{c}\text { Actual } \\
(\%)\end{array}$ \\
& & & $(\%)$ & \\
\hline I & $2.5 / 0$ & 10.17 & $11.52( \pm 1.79)$ & $15-20$ & $12.0^{*}$ \\
II & $2.5 / 3$ & 13.77 & $13.02( \pm 1.58)$ & $5-8$ & 5.5 \\
III & $3.5 / 0$ & 12.83 & $15.46( \pm 2.12)$ & $15-20$ & $17.0^{*}$ \\
IV & $3.5 / 3$ & 17.87 & $18.56( \pm 3.00)$ & $5-8$ & 4.0 \\
\hline
\end{tabular}

${ }^{\star}$ Repeated measures one-way analysis of variance significant at $\mathrm{D} \leq .05$.

Table 4

Validation of Predicted Oxygen Consumption.

\begin{tabular}{ccccc}
\hline Phase & $\begin{array}{c}\text { Mean difference } \\
\left(\mathrm{ml} \cdot \mathrm{kg}^{-1} \cdot \mathrm{min}^{-1}\right)\end{array}$ & $\mathrm{R}$ & $\begin{array}{c}\mathrm{SEE} \\
\left(\mathrm{ml} \cdot \mathrm{kg}^{-1} \cdot \mathrm{min}^{-1}\right)\end{array}$ & $\begin{array}{c}\text { Total error } \\
\left(\mathrm{ml} \cdot \mathrm{kg}^{-1} \cdot \mathrm{min}^{-1}\right)\end{array}$ \\
I & $-1.35^{*}$ & .86 & 0.95 & 2.56 \\
II & 0.75 & .66 & 0.93 & 1.85 \\
III & $-2.63^{*}$ & .94 & 0.76 & 4.23 \\
IV & -0.69 & .71 & 2.22 & 3.03 \\
\hline
\end{tabular}

"Repeated measures one-way analysis of variance significant at $\mathrm{p} \leq .05$. 
of the mean error values and the SEE values resulted in total errors (TE) ranging from 1.85 to $4.23 \mathrm{ml}^{\mathrm{kg}}-1 \cdot \mathrm{min}^{-1}$.

\section{Discussion of Results}

The purpose of this investigation was to determine if the metabolic equation for walking published by the American College of Sports Medicine (ACSM) could be used to accurately predict the energy requirements of walking in an older female population. The results of this investigation indicated that the ACSM prediction equation could be used, within the stated limitations, to estimate the energy requirements of $0 \%$ and $3 \%$ graded treadmill walking at speeds of 2.5 and 3.5 miles per hour in females between the ages of 55 and 78 years. According to Guidelines for Exercise Testing and Prescription (ACSM, 1986), the equation can be used to estimate with reasonable accuracy the oxygen requirements for graded walking between speeds of 1.9 and 3.7 miles per hour. The equation is relatively accurate for most speeds and grades but has some limitations. The limitations are that the equation is expected to underestimate the actual $\mathrm{VO}_{2}$ requirements of level walking by 15 to $20 \%$ and of walking up a $3 \%$ grade by 5 to $8 \%$. In this study the prediction equation underestimated the $\mathrm{VO}_{2}$ requirements of the two level walking phases by 12 and $17 \%$. In the graded phases the prediction equation overestimated actual $\mathrm{VO}_{2}$ by $5.5 \%$ in phase $I I$ and underestimated $\mathrm{VO}_{2}$ by $4 \%$ in phase IV.

The equation proved to be a less accurate predictor for level walking than for graded walking in this investigation. The results demonstrated a significant difference between the mean predicted $\mathrm{VO}_{2}$ and actual $\mathrm{VO}_{2}$ in the two level phases, phase I and III, of the treadmill protocol. In phase I the 
equation underestimated the actual $\mathrm{VO}_{2}$ requirement of level walking at 2.5 miles per hour by $1.35 \mathrm{ml} \cdot \mathrm{kg}^{-1} \cdot \mathrm{min}^{-1}$. This is equivalent to an underestimate of $12 \%$. The largest mean error occurred in phase III, where the equation underestimated the actual $\mathrm{VO}_{2}$ requirement of walking at 3.5 miles per hour at a $0 \%$ grade by $17 \%$, or $2.63 \mathrm{ml} \cdot \mathrm{kg}^{-1} \cdot \mathrm{min}^{-1}$. For the $3 \%$ graded walking phases, the mean errors between the predicted and the actual $\mathrm{VO}_{2}$ were nonsignificant. In phase II, walking at 2.5 miles per hour, the equation overestimated the actual $\mathrm{VO}_{2}$ requirement by $5.5 \%$, or $0.75 \mathrm{ml}^{\mathrm{kg}}-1 \cdot \mathrm{min}^{-1}$. In phase IV, while walking at 3.5 miles per hour, the equation underestimated the actual $\mathrm{VO}_{2}$ by only $4 \%$, or $0.69 \mathrm{ml}^{1} \mathrm{~kg}^{-1} \cdot \mathrm{min}^{-1}$.

The results of this study compare with a study conducted by Montoye et al. (1985) The results of the Montoye et al. (1985) investigation showed the ACSM prediction equation to underestimate the mean $\mathrm{VO}_{2}$ requirement of adult males by approximately $3-4 \mathrm{ml} \cdot \mathrm{kg}^{-1} \cdot \mathrm{min}^{-1}$ during level treadmill walking at 3 miles per hour, and by approximately $1.0 \mathrm{ml} \cdot \mathrm{kg}^{-1} \cdot \mathrm{min}^{-1}$ when walking up a $3 \%$ grade at 3 miles per hour. Compared to the results of this study conducted with older females, the mean errors between the predicted and actual $\mathrm{VO}_{2}$ requirements were approximately between 1 and $3 \mathrm{ml} \cdot \mathrm{kg}^{-1} \cdot \mathrm{min}^{-1}$ in the level walking phases and 0.5 and $1.5 \mathrm{ml} \cdot \mathrm{kg}^{-1} \cdot \mathrm{min}^{-1}$ in the $3 \%$ graded phases.

The total error (TE) values also demonstrated that the accuracy of the prediction equation was greater with graded walking than it was with level walking. At 2.5 miles per hour the TE for level walking was $2.56 \mathrm{ml} \cdot \mathrm{kg}^{-1} \cdot \mathrm{min}^{-1}$ in phase $\mathrm{I}$, compared to $1.85 \mathrm{ml} \cdot \mathrm{kg}^{-1} \cdot \mathrm{min}^{-1}$ for walking up a $3 \%$ grade in phase III. The greatest TE occurred during level walking at 3.5 miles per hour in phase III and was calculated to be $4.23 \mathrm{ml} \cdot \mathrm{kg}^{-1} \cdot \mathrm{min}^{-1}$, compared to $3.03 \mathrm{ml} \cdot \mathrm{kg}^{-1} \cdot \mathrm{min}^{-1}$ 
for walking up a $3 \%$ grade in phase IV. The total error combines the effects of the mean error and SEE values. This combined effect revealed percent differences between the predicted $\mathrm{VO}_{2}$ values and actual $\mathrm{VO}_{2}$ values for level walking to be 25 to $33 \%$ and 13 to $17 \%$ for walking up a 3\% grade. Expressed in terms of METS, the total errors indicated that the equation underestimated the actual $\mathrm{VO}_{2}$ requirements of level walking in phase I and phase III by approximately 0.75 to 1.2 METS. In walking up a $3 \%$ grade in phases II and IV, the difference between the estimated $\mathrm{VO}_{2}$ and actual $\mathrm{VO}_{2}$ was approximately 0.5 to 0.87 METS.

The ACSM guidelines also state that the measured oxygen uptake rate at any given walking speed/grade will vary by approximately $7 \%$ between individuals. The group variances, expressed as a percentage, in each phase of the excercise protocol in this study were greater than the expected $7 \%$ variation. The variances in this study ranged from $12 \%$ in phase 11 to $16 \%$ in phase IV. These variations are more in line with the $15 \%$ variation found by Mahadeva et al. (1953) and reported by Astrand and Rodahl (1986). The variances found in this study would indicate that there were differences in the mechanical efficiencies of the subjects when walking at the speeds and grades used in this study. Research conducted by Ralston (1958) showed that for each individual, there exists a walking speed at which the energy required to travel a unit distance is minimized. This would be shown graphically as a parabolic curve with energy requirement $\left(\mathrm{VO}_{2}\right)$ on the $y$-axis and speed of walking on the $x$-axis. In other words, the lowest portion of the curve would define, for an individual, the optimal speed of walking which would elicit a maximal mechanical efficiency and a minimal energy requirement (Workman \& 
Armstrong, 1963). For some individuals jogging may have been more efficient that walking at the speeds and grades used in this study. Therefore, the energy expenditure for each individual would be quite different and could not be predicted from speed and grade alone. This variation in optimal energy expenditure between individuals would elicit a greater than expected difference between the predicted $\mathrm{VO}_{2}$ and the actual $\mathrm{VO}_{2}$ values.

\section{Conclusions}

Within the limits of this study the following conclusions were made. The metabolic equation for graded walking published by the American College of Sports Medicine can be used to predict the mean $\mathrm{VO}_{2}$ requirements of females between the ages of 55 and 78 years within the limitations stated in the Guidelines for Exercise Testing and Prescription (ACSM, 1986). The equation is expected to be less accurate in estimating $\mathrm{VO}_{2}$ for level walking than it is for graded walking. Underestimates of 15 to $20 \%$ are expected with level walking and underestimates of 5 to $8 \%$ are expected with walking up a $3 \%$ grade.

The equation was less accurate in predicting the oxygen requirement of level walking than graded walking. The mean difference between the actual mean $\mathrm{VO}_{2}$ and predicted mean $\mathrm{VO}_{2}$ in the two level phases were significant. The mean difference between the actual mean $\mathrm{VO}_{2}$ and the predicted mean $\mathrm{VO}_{2}$ in the two graded phases of the exercise protocol were not significant. The equation underestimated the actual mean $\mathrm{VO}_{2}$ value by 12 to $17 \%$ in the level phases of the walking protocol. It overestimated the actual mean $\mathrm{VO}_{2}$ requirement by $5.5 \%$ in phase II of the graded walking protocol and underestimated the actual $\mathrm{VO}_{2}$ requirement by $4 \%$ in phase IV of the graded walking protocol. 
Since the total errors were as great as 1 MET, the prediction equation should be applied only as a guideline or rough estimate of the actual $\mathrm{VO}_{2}$ requirements of walking for females between the ages of 55 and 78 years.

\section{Weaknesses of the Study}

The weaknesses of the study were the small sample size of subjects and that the resting oxygen uptake rate was not measured. With larger sample sizes the distribution of scores is more likely to resemble a normal distribution and the sample mean is more likely to approximate the population mean. The majority of the subjects in this study were classified in the excellent fitness category. Individuals with poor to average levels of fitness were not well represented in this study.

The equation is made up of three components added together: a horizontal $\mathrm{VO}_{2}$ component; a vertical $\mathrm{VO}_{2}$ component; and a resting $\mathrm{VO}_{2}$ component. Since individual resting oxygen uptake values were not measured, there is no way to determine if the variances between the predicted and actual oxygen uptake rates in each of the four phases of the exercise protocol were in part due to differences between the predicted resting $\mathrm{VO}_{2}$ and actual resting $\mathrm{VO}_{2}$.

\section{Recommendations for Future Research}

Within the limits of this study the following recommendations are made:

1) Future research should investigate walking and running at treadmill speeds and grades different than the speeds and grades used in this study.

2) Future research should determine if there are differences between the resting oxygen uptake rate and estimated oxygen uptake rate of

$3.5 \mathrm{ml} \cdot \mathrm{kg}^{-1} \cdot \mathrm{min}^{-1}$ in various age groups. 
3. Future research should investigate the validity of the ACSM prediction equations for the leg ergometer, arm ergometer, and stepping.

4. Future research should determine the validity of the unit horizontal and unit vertical $\mathrm{VO}_{2}$ costs of the prediction equation for walking in various age groups. 


\section{References}

American College of Sports Medicine. (1986). Guidelines for exercise testing and prescription (3rd ed.). Philadelphia: Lea \& Febiger.

Astrand, P. \& Rodahl, K. (1986). Textbook of work physiology: Physiological basis of exercise (3rd ed.). New York: McGraw-Hill.

Balke, B. \& Ware, R.W. (1959). An experimental study of "physical fitness" of air force personnel. United States Armed Forces Medical Journal, 10, 675-688.

Bobbert, A.C. (1960). Energy expenditure in level and grade walking. Journal of Applied Physiology, 15, 1015-1021.

Bruce, R.A. (1971). Exercise testing of patients with coronary heart disease. Annals of Clinical Research, $3,323$.

Consolazio, C.F., Johnson, R.E. \& Pecora, L.J. (1963). Physiological measurements of metabolic functions in man. New York: McGraw-Hill.

Cotes, J.E. \& Meade, F. (1960). The energy expenditure and mechanical energy demand in walking. Ergonomics, 3 , 97-119.

Dill, D.B. (1965). Oxygen used in horizontal and grade walking and running on the treadmill. Journal of Applied Physiology, 20, 19-22.

Dill, D.B., Horvath, S.M. \& Craig, F.N. (1958). Responses to exercise as related to age. Journal of Applied Physiology, 12, 195-196.

Erickson, L., Simonson, E., Taylor, H.L., Alexander, H. \& Keys, A. (1946). The energy cost of horizontal and grade walking on the motor-driven treadmill. American Journal of Physiology, 145, 391-401. 
Fox, E.L., Bowers, R.W. \& Foss, M.L. (1988). The physiological basis of physical education and athletics. New York: Saunders College Publishing.

Giancoli, D.C. (1980). Physics. New Jersey: Prentice-Hall.

Givoni, B. \& Goldman, R.F. (1971). Predicting metabolic energy cost. Journal of Applied Physiology, 30, 429-433.

Grimby, G. \& Soderholm, B. (1962). Energy expenditure of men in different age groups during level walking and bicycle ergometry. The Scandinavian Journal of Clinical \& Laboratory Investigation, 14, 321 328.

Jones, N.L. (1988). Clinical exercise testing. Philadelphia: W.B. Saunders. Kenney, R.A. (1982). Physiology of Aging. Chicago: Year Book Medical Publishers.

Mahadeva, K., Passmore, R. \& Woolf, B. (1953). Individual variations in the metabolic cost of standardized exercises: The effects of food, age, sex and race. Journal of Physiology, 121, 225-231.

Montoye, H.J. (1982). Age and oxygen utilization during submaximal treadmill exercise in males. Journal of Gerontology, 37, 396-402.

Montoye, H.J., Ayen, T., Nagle, F. \& Howley, E.T. (1985). The oxygen requirement for horizontal and grade walking on a motor-driven treadmill. Medicine and Science in Sports and Exercise, 17, 640-645.

Montoye, H.J., Cunningham, D.A., Welch, H.G. \& Epstein, F.H. (1970). Laboratory methods of assessing metabolic capacity in a large epidemiologic study. American Journal of Epidemiology, 91, 38-47. 
Nagle, F.J., Balke, B. \& Naughton, J.P. (1965). Gradational step tests for assessing work capacity. Journal of Applied Physiologv, 20, 745-748.

Passmore, R. \& Durnin, J.V.G.A. (1955). Human energy expenditure.

Physiological Reviews, 35, 801-840.

Ralston, H.J. (1958). Energy-speed relation and optimal speed during level walking. Int. Z. angew. Physiol. einscl. Arbeitsphysiol., 17, 277-283.

Shvartz, E. \& Reibold, R.C. (1990). Aerobic fitness norms for males and females aged 6 to 75 years: A review. Aviation Space and Environmental Medicine, 61, 3-11.

Smith, H.M. (1922). Gaseous exchange and physiological requirements for level and grade walking (Report No. 309). Washington DC: Carnegie Institution of Washington.

Van Der Walt, W.H. \& Wyndham, C.H. (1973). An equation for prediction of energy expenditure of walking and running. Journal of Applied Physiology, 34, 559-563.

Webb, P., Saris, W.H.M., Schoffelen, P.F.M., Van Ingen Schenau, G.J. \& Ten Hoor, F. (1988). The work of walking: a calorimetric study. Medicine and Science in Sports and Exercise, 20, 331-337.

Workman, J.M. \& Armstrong, B.W. (1963). Oxygen cost of treadmill walking. Journal of Applied Physiology, 18, 798-803. 


\begin{abstract}
APPENDIX A
STUDY TO INVESTIGATE THE VALIDITY OF THE AMERICAN COLLEGE OF SPORTS MEDICINE'S METABOLIC PREDICTION EQUATION FOR WALKING IN OLDER FEMALES
\end{abstract}

\title{
STATEMENT OF INFORMED CONSENT - FORM FOR CARDIOVASCULAR \\ FITNESS TESTING AND SUBMAXIMAL GRADED TREADMILL WALKING
}

\section{Invitation to Participate}

You are invited to participate in a study investigating the validity of the American College of Sports Medicine's metabolic equation for graded treadmill walking. Participation will involve cardiovascular fitness testing, height and weight measurements, and submaximal walking on a motor driven treadmill. This study will require two one hour testing sessions which will occur within two weeks of each other. The first session will be conducted at DeAnza College Exercise Physiology Laboratory in Cupertino; the second session will be conducted in the Exercise Physiology/Biomechanics Laboratory at San Jose State University.

\section{Basis for Selection}

You have been selected as a participant because you are a healthy female 55 years of age or older. Should you decide to participate, your cardiovascular fitness test will be reviewed by a physician, and your responses to a health history questionnaire will be reviewed by an exercise physiologist. If both are satisfactory, you will be asked to participate in the tests described 
below. Written approval from your family physician must also be obtained prior to participation.

\section{Purpose of the study}

The purpose of this study is to cross-validate the American College of Sports Medicine's metabolic equation for graded treadmill walking with a subject population of females 55 years or older.

\section{Explanation of Procedures}

\section{Testing Sessions}

The research study will require two testing sessions which will occur within two weeks of each other. The first testing session will involve assessment of cardiovascular fitness. The second testing session will involve submaximal walking on a motor driven treadmill.

\section{Maximal Treadmill Test for Cardiovascular fitness}

\section{(approximately 1 hour required)}

Your maximal oxygen uptake rate and maximal heart rate will be determined from a maximal treadmill test which will involve walking and/or slow jogging with progressively increasing speed and incline every three minutes until voluntary exhaustion. During the test your expired air will be collected through a mouthpiece connected to rubber tubing. Your heart rate will be monitored by five electrodes attached to your chest. Following the measurement of resting heart rate and blood pressure, you will begin a warmup walk on the treadmill. Immediately following the warm-up period, the speed of the treadmill will be $1.7 \mathrm{mph}$ and the grade (incline) will be $10 \%$. Thereafter, the speed increases by . $8 \mathrm{mph}$, along with a $2 \%$ increase in the elevation of the treadmill every three minutes until voluntary exhaustion. The test will end when 
you indicate that you no longer wish to continue due to pain, anxiety or the perception of any unusual sensation or feeling not normally experienced with exercise, or your responses (heart function, respiration, and/or physical appearance) indicate that you should not continue or you have reached your maximal effort. It is anticipated that the test period, including the warm-up, will last 15 to 20 minutes. Following completion of this test, the speed will be reduced and the grade brought down to $0 \%$ for a cool-down walk. The cool down will continue until your heart rate is at or near resting values.

\section{Submaximal graded treadmill walking}

(approximately 1 hour required)

Your metabolic requirements (oxygen uptake and carbon dioxide production rates) and caloric expenditure will be determined during 24 minutes of steady-state simulated treadmill walking. Your expired air will be collected through a mouthpiece connected to rubber tubing. Your heart will be monitored by five electrodes attached to your chest. Following measurement of resting heart rate and blood pressure, you will warm-up for the submaximal test by walking at a comfortable speed and $0 \%$ grade for a period of approximately five minutes. Immediately following completion of the warm-up period, you will begin walking at $2.5 \mathrm{mph}$ at a $0 \%$ grade for six minutes; the grade will then increase to $3 \%$ while the speed remains constant for the next six minutes; the grade will then return to $0 \%$ but the speed will now be increased to $3.5 \mathrm{mph}$, you will again walk for six minutes at this speed and grade; finally the grade will increase to $3 \%$ while the speed remains at $3.5 \mathrm{mph}$ for six minutes; a cool-down period will then begin where you will walk at a comfortable speed at a $0 \%$ grade until your heart rate returns to at or near resting values. This test will be 
terminated if you indicate that you no longer wish to continue for any reason including pain, anxiety or the perception of any unusual sensations or feelings not normally associated with exercise or your responses (heart function, respiration, and/or physical appearance) indicate that you should not continue.

\section{Risks and Discomforts}

\section{Cardiorespiratory Endurance and Submaximal Treadmill Walking}

Some discomfort and dryness in the mouth, throat, and chest as result of the restricted breathing, may occur. You may feel lightheaded, fatigued, and slightly nauseous for a short time following the tests. Also the discomforts commonly associated with exercise, such as sweating, increased heart rate, increased breathing rate, elevated body temperature, and muscle soreness, may occur. You should also be aware that these tests may involve the possible risk of falls and muscle or joint injuries. Heart attack is also a possible risk. Every effort will be made to minimize discomfort and risk through preliminary testing and observations by trained personnel during testing. When you are at or near maximal effort exercise you may experience abnormal blood pressure, fainting, and/or dizziness, muscle fatigue or cramps, and abnormalities in heart beat. If abnormalities are detected in pulmonary function or electrocardiographic recordings, the tests will be terminated and you will be excluded from this investigation.

\section{Benefits for Participation in Study}

You will benefit from this study by receiving feedback on your cardiovascular fitness. You will also receive feedback on your metabolic requirements (oxygen uptake rate and heart rate) and caloric expenditure during graded treadmill walking. 
The metabolic equation being cross-validated is sometimes used in clinical settings for exercise prescription, rehabilitation progress and employment suitability. The equations were based on studies done on younger male individuals, therefore an older female may be at a severe disadvantage if the equations are not making valid estimates of energy expenditure.

\section{Assurance of Confidentiality}

The results of this investigation may be used for research publication and presentation. Your right to confidentiality will be protected unless your express consent is granted prior to the publication or presentation.

\section{Withdrawl from Study}

You may withdraw your consent and discontinue your participation in this study any time (including during the testing) without prejudice. You may also decline to answer any question or item on the health history questionnaire.

Testing will be supervised and conducted at San Jose State by Dr. Craig Cisar, Exercise Physiologist and Certified Exercise Test Technologist, and Debra Fegan, Certified Exercise Test Technologist; at DeAnza College by Rich Schroeder and Wendy Russum, both Exercise Physiologists and Certified Exercise Test Technologists, and either Dr. Ronald Freeman or Dr. James Ratcliff, both supervising physicians for DeAnza's Exercise Physiology Laboratory. Certified CPR personnel will be present during the testing.

If you have any questions about the investigation now or during the testing, please feel free to ask. If additional questions come-up later or in the case of an emergency, call Debra Fegan at (408) 554-0522 or Dr. Craig Cisar at (408) 924-3019. Any questions or complaints about the procedures may be presented to Dr. James Bryant, Chairperson of the Department of Human 
Performance, at (408) 924-3010. For questions or complaints about research subject's rights or in the event of research related injury, contact Dr. Serena Standford, Associate Academic Vice President of Graduate Studies and Research, at (408) 924-2480.

\section{Consent}

By signing this form, you are agreeing that:

(a) you decided to participate in this study having read the information provided above.

(b) you understand the discomforts and risks involved.

(c) you understand you can withdraw at any time.

(d) you understand that your name will be kept confidential except with your express consent.

Signature Date

Print Name

Signature of Witness

Signature of Investigator 


\section{APPENDIX B}

\section{HEALTH HISTORY QUESTIONNAIRE}

NAME

DATE

BIRTHDATE AGE HEIGHT WEIGHT

1. Have you ever had an exercise stress test before?

$$
1=\text { Yes } \quad 2=\text { No }
$$

2. If yes, please give date and location

3. Reason for previous test (circle one).

1 = Diagnostic

2 = Functional

$3=$ Exercise Prescription

$4=$ Other

4. Results of previous test (if known)

5. Has a physician ever made any recommendations relative to limiting your levels of physical exertion?

$$
1=\text { Yes } 2 \text { = No }
$$

6. If yes, what limitations were recommended 
7. How often do you exercise? (circle one)

$$
1=\text { none }
$$

$2=1-2$ times per week

$3=3$ times per week

$4=4$ times per week

$5=5$ times per week

8. Describe the intensity of your exercise (circle one)

$1=$ none

2 = light (e.g. casual walking, golf)

$3=$ moderate (e.g. brisk walking, jogging, cycling, swimming)

4 = heavy (e.g. running, high intensity sport activity)

9. How much time per week do you spend exercising (circle one)

$$
\begin{aligned}
1 & =\text { none } \\
2 & =\text { less than } 30 \text { minutes per week } \\
3 & =30 \text { minutes per week } \\
4 & =45 \text { minutes per week } \\
5 & =1 \text { hour per week } \\
6 & =1.5 \text { hours per week } \\
7 & =2 \text { hours per week } \\
8 & =2.5 \text { hours per week } \\
9 & =3 \text { hours per week } \\
10 & =3.5 \text { hours per week } \\
11 & =4 \text { hours per week } \\
12 & =4.5 \text { hours per week } \\
13 & =5 \text { hours per week } \\
14 & =\text { more than } 5 \text { hours per week }
\end{aligned}
$$


10. What types of exercise do you engage in? (circle one)

$1=$ none

$2=$ walking

$3=$ jogging/running

4 = swimming

$5=$ cycling

$6=$ team sports (basketball, softball, soccer, etc.)

$7=$ raquet sports

$8=$ weight training

11. What condition or shape do you consider yourself to be in now? (in terms of physical fitness)

$1=$ poor

2 = fair

$3=$ good

4 = excellent

12. Have you ever smoked cigarettes? (circle one)

$1=$ no

2 = currently smoke cigarettes

$3=$ quit smoking within the past 6 months

4 = quit smoking within the past 12 months

5 = quit smoking longer than 12 months ago

13. How much do you smoke per day? (circle one)

$1=$ none

$2=0.5$ packs or less

$3=1$ pack

$4=1.5$ packs

$5=2$ packs

$6=$ more than 2 packs 
14. How long have you smoked? (circle one)

1 = don't smoke

$2=5$ years or less

$3=6-10$ years

$4=11-15$ years

$5=16-20$ years

$6=21$ years or more

15. Indicate which of the following apply to you (circle all that apply)

$1=$ high blood pressure

2 = high blood fats or cholesterol

3 = cigarette smoking

$4=$ known heart disease or abnormalities

$5=$ family history of heart disease (parents or siblings before age 50 )

$6=$ sedentary lifestyle

7 = stressfull lifestyle at home or at work

$8=$ diabetes mellitus

$9=$ gout (high uric acid)

10 = obesity

11 = edema

$12=$ peripheral circulatory disorder

16. When was your last physical examination?

17. Any major illnesses or physical problems at that time or any time in the past?

$1=$ Yes If yes, describe completely

$2=\mathrm{No}$ 
18. Any surgery or hospitalization in the past? $1=$ Yes If yes, describe completely

$2=$ No

19. Are you currently taking any medications? (prescription or over-thecounter) $1=$ Yes If yes, list medications and dosages

$2=$ No

20. Are you allergic to any medications?

$1=$ Yes If yes, list medications

$2=$ No

21. Do you have, or have you ever had, any of the following? (circle all that apply)

$1=$ any bone or joint injuries

$2=$ any muscular injuries

$3=$ muscle or joint pain following exercise

$4=$ limited flexibility

$5=$ any back injury or pain

$6=$ any knee or ankle pain

7 = any musculoskeletal problems which might limit your ability to exercise (e.g. arthritis, multiple sclerosis)

8. $=$ hernia

Please fully explain any items you circled 
22. Do you now have, or have you ever had, any of the following (circle all that apply)

$$
\begin{aligned}
1 & =\text { heart murmurs } \\
2 & =\text { any chest pain at rest } \\
3 & =\text { any chest pain upon exertion } \\
4 & =\text { pain or numbness in left arm, jaw, neck } \\
5 & =\text { any heart palpitations } \\
6 & =\text { fainting or dizziness } \\
7 & =\text { extreme weakness } \\
8 & =\text { mental confusion } \\
9 & =\text { daily coughing } \\
10 & =\text { coughing that produces sputum } \\
11 & =\text { shortness of breath at rest } \\
12 & =\text { shortness of breath upon exertion } \\
13 & =\text { any known respiratory diseases or dysfunctions } \\
14 & =\text { epilepsy }
\end{aligned}
$$

Please fully explain any items you circled

23. Have you ever had any neurological problems?

$$
\begin{aligned}
& 1=\text { Yes If yes, describe completely } \\
& 2=\text { No }
\end{aligned}
$$




\section{APPENDIX C}

Your patient

has volunteered to participate in a research study being conducted through the Human Performance Department at San Jose State University. A cardiovascular fitness test will be conducted at DeAnza College's Exercise Physiology Laboratory as a part of this study. The test protocol involves walking/jogging on a motorized treadmill until the subject voluntarily terminates the test. Maximal oxygen uptake and heart rate will be determined from the test. A physician and exercise physiologists will be present throughout the test. Oxygen consumption, ECG, and heart rate will be continuously monitored during the test. DeAnza College requires that all participants over the age of 35 years obtain physician's approval prior to taking the cardiovascular fitness test.

Thank you for your cooperation,

Debra Fegan, Graduate Student

Human Performance Department

San Jose State University

(408) 554-0522

Patient's Name: Date:

There are no medical contraindications that I know of to prevent this patient from taking a cardiovascular fitness test at the DeAnza College Exercise Physiology Laboratory.

There are medical problems that place this patient at increased risk, but he/she may take a cardiovascular fitness test at DeAnza College Exercise Physiology Laboratory.

Comments:

This patient should not be allowed to take a cardiovascular fitness test at the DeAnza College Exercise Physiology Laboratory.

(signature)

(Physicians's name typed or stamp) (telephone)

(address) 